\title{
Foreign Investment, Urban Unemployment, and Informal Sector
}

\author{
Shigemi Yabuuchi \\ Nagoya City University \\ Hamid Beladi \\ North Dakota State University \\ Gu Wei \\ Kansai Research Institute
}

\begin{abstract}
In this paper we extend the Harris-Todaro model to include an urban informal sector. The effects of exogenous inflow of foreign capital on outputs, unemployment and welfare are examined in the model where the product of the informal sector is used as an industrial input in the urban formal sector. We also analyze the implications of the capital inflow for income distribution.
\end{abstract}

- JEL Classification: F21, R23, O17

- Key words: Harris-Todaro model; Foreign investment; Welfare

\section{Introduction}

The relationship between protection and capital accumulation has often been discussed, particular attention being paid to its welfare implication. Johnson (1967) and Bhagwati $(1958,1968,1973)$ demonstrated the possibility of immiserizing growth under some distorted situations. The essence of their results is now well

\footnotetext{
*Corresponding address: Shigemi Yabuuchi, Department of Economics Nagoya City University Yamanohata, Mizuho Nagoya 467-8501 Japan Tel/Fax: +81-52-872-5739 Email: yabuuchi@econ. nagoya-cu.ac.jp

(C2005-Center for International Economics, Sejong Institution, All Rights Reserved.
} 
known as the following proposition:

"The capital inflow must reduce the host-country welfare if the country imports the capital-intensive commodity under tariff protection and foreign capital receives the full value of its marginal product. [Uzawa (1969), Hamada (1974), and Brecher and Alejandro (1977)]".

Several authors have extensively studied the validity of the proposition. Yabuuchi (1982) confirmed their results and extended it by deriving a sufficient condition for tariff immiserization. Brecher and Findlay (1983) and Casas (1985) examined the issue in the context of a model with sector-specific inputs. The analysis was extended also to the case of import quotas by Dei (1985). In a related study, various aspects of duty free zones and export processing zones have been discussed by trade theorists such as Rodriguez (1976), Hamilton and Svensson (1987), Miyagiwa (1986, 1993), Young (1987, 1992), Young and Miyagiwa (1987), Beladi and Marjit (1992) and Yabuuchi (1997).

In addition, there are some attempts to examine the effects of foreign capital inflow under tariff protection in the presence of unemployment. Khan (1982) showed the validity of the proposition even in the mobile capital Harris-Todaro model (hereafter HT model), while Grinols (1991) questioned the validity in the presence of an informal sector. Chandra and Khan (1993), Chao and Yu (1991, 1994), Gupta (1994, 1995), and Beladi and Marjit (2000) reexamined the argument in various situations. On the other hand, with differing emphases, Yabuuchi (1993), Chao and Yu (1996), Din (1996), and Beladi and Yabuuchi (2001) investigated the effects of tariff and subsidy policies in the presence of international capital mobility and unemployment.

In the present paper, we employ the same model as Beladi and Yabuuchi (2001) and examine the different issues, that is, the effects of exogenous inflow of foreign capital on the manufacturing output, unemployment, welfare and income distribution. The model extends the Harris-Todaro model to include an urban informal sector where the product of the informal sector is used as an industrial input in the urban formal sector. Grinols (1991) examined the issue by using a similar model. The differences between our model and Grinols' are twofold. First, the informal good is a pure intermediate good in our model, while it is a final consumption good in his model. Second, there is no explicit unemployment in his model. However, we introduce urban unemployment as well as an informal sector. Our main 
messages are as follows. Foreign investment into the urban formal sector increases the output of the sector under protection. The investment reduces unemployment and improves welfare under certain conditions. The results show sharp contrast to the conventional wisdom. We derive the precise conditions for the results and identify them. In addition, the investment redistributes income from capital to labor in the economy as a whole.

The paper is organized as follows. Section 2 presents the model and basic assumptions. We examine the effects of an exogenous inflow of foreign capital on output, unemployment and welfare in section 3 . The implication of the investment for income distribution is discussed in section 4 . The final section includes concluding remarks on the findings.

\section{The Model and its Assumptions}

We consider a small open economy that consists of three sectors, the urban formal sector ( manufacturing sector $m$ ), urban informal sector (intermediate sector i) and rural sector (agricultural sector $a$ ). Production of agricultural and informal goods requires labor and sector-specific capital. The manufacturing sector utilizes labor, sector-specific capital and the informal good. Each sector utilizes strictly quasi-concave and constant returns to scale technology, and factors exhibit positive but diminishing marginal products. Thus, production functions in the urban manufacturing sector, $X_{m}$, urban informal sector, $X_{i}$, and rural agricultural sector, $X_{a}$, are given by,

$$
\begin{gathered}
X_{m}=F^{m}\left(K_{m}, L_{m}, R\right), \\
X_{i}=F^{i}\left(K_{i}, L_{i}\right), \\
X_{a}=F^{a}\left(K_{a}, L_{a}\right),
\end{gathered}
$$

where $K_{j}$ and $L_{j}$ denote the employment of capital and labor, respectively, in the $j$ th sector $(j=m, i, a)$. A distinguishing feature of our model is the presence of an urban informal sector that produces $X_{i}$ and is used as a pure intermediate input $(R)$ in the production of $X_{m}$. The agricultural good is exported at the normalized price of unity. The manufacturing good is an importable good with world price $p^{*}$ but whose domestic price $p$ is increased by an ad valorem tariff $t$, i.e., $p=(1+t) p^{*}$. 
Following Harris and Todaro (1970), it is assumed that the real wage rate in manufacturing $\left(w_{m}\right)$ is rigid owing to some political and/or institutional considerations while wage rate in the agricultural sector $\left(w_{a}\right)$ is flexible. It is also assumed that the informal wage rate is constant and given

$$
w_{i}=\alpha w_{m}
$$

where $0<\alpha<1$, represents the distortionary wage differential between the two sectors. As an example of this sort of wage differential, Beladi and Yabuuchi (2001) suggested the relation between the subcontract and parent firms as discussed in detail below. The subcontract firms are characterized by a low wage rate suppressed by the parent firm.

The characteristic feature of the original HT model is that in the labor market equilibrium, the rural wage rate $\left(w_{a}\right)$ equals the expected wage income in the manufacturing sector, which is by definition the manufacturing wage rate $\left(w_{m}\right)$ times the probability of finding a job in the manufacturing sector. Let $L_{u}$ be unemployed in the urban area. Since the probability of finding a job in the manufacturing sector is $L_{m} /\left(L_{m}+L_{u}\right)$ in the original HT model without the informal sector, then the expected wage in the manufacturing sector is $w_{m} L_{m} /\left(L_{m}+L_{u}\right)$. Thus, the labor allocation mechanism between rural and urban areas is expressed as $w_{m} L_{m} /\left(L_{m}+L_{u}\right)=w_{a}$.

Introducing the informal sector to the HT framework would modify the labor allocation mechanism such that in the labor market equilibrium, the rural wage rate $\left(w_{a}\right)$ equals the expected wage income in the urban area (that is, the manufacturing and informal sectors). Since the probability of finding a job in the manufacturing sector is $L_{m} /\left(L_{m}+L_{i}+L_{u}\right)$ in the present case, then the expected wage in the manufacturing sector is $w_{m} L_{m} /\left(L_{m}+L_{i}+L_{u}\right)$. Similarly, the expected wage in the informal sector is $w_{i} L_{i} /\left(L_{m}+L_{i}+L_{u}\right)$. Thus, the expected wage in the urban area (the manufacturing and informal sectors) is $\left(w_{m} L_{m}+w_{i} L_{i}\right) /\left(L_{m}+L_{i}+L_{u}\right)$. Therefore, the labor allocation mechanism between rural and urban areas is expressed as

$$
\left(w_{m} L_{m}+w_{i} L_{i}\right) /\left(L_{m}+L_{i}+L_{u}\right)=w_{a},
$$

or alternatively

$$
\left(w_{m}+\mu w_{\mathrm{i}}\right)=w_{a}(1+\mu+\lambda),
$$


where and $\mu=L_{i} / L_{m}$ and $\lambda=L_{l} / L_{m}$.

The labor market equilibrium is expressed, in addition to (4) and (5) above, as

$$
\begin{gathered}
w_{m}=p F_{L}^{m}\left(K_{m}, L_{m}, R\right), \\
w_{i}=q F_{L}^{i}\left(K_{i}, L_{i}\right), \\
w_{a}=F_{L}^{a}\left(K_{a}, L_{a}\right),
\end{gathered}
$$

where $F_{L}^{j}=\partial F^{j} / \partial L_{j},(j=m, i, a)$ and $q$ is the price of the informal good. Similarly, in the capital market equilibrium, we have

$$
\begin{gathered}
r_{m}=p F_{K}^{m}\left(K_{m}, L_{m}, R\right), \\
r_{i}=q F_{K}^{i}\left(K_{i}, L_{i}\right), \\
r_{a}=F_{K}^{a}\left(K_{a}, L_{a}\right),
\end{gathered}
$$

where $r_{j}$ is the rental of capital in each sector $(j=m, i, a)$. In the informal good market, the marginal value product of the intermediate good equals its price. Thus, we have

$$
q=p F_{R}^{m}\left(K_{m}, L_{m}, R\right)
$$

The employment condition in the labor market is

$$
L_{a}+L_{m}(1+\mu+\lambda)=L
$$

The labor allocation in the economy is shown in Figure 1, where $m m$, ii and $a a$ are the marginal value products of labor in the domestic manufacturing, informal and agricultural sectors, respectively. 00' is the amount of labor endowment. First, $L_{m}$ is determined at point $M$ since $w_{m}$ is fixed. From (4) and (5) we have $(1+\alpha \mu) w_{m}$ $=w_{a}(1+\mu+\lambda)$ or

$$
(1+\alpha \mu) w_{m} L_{m}=w_{a}\left(L_{m}+L_{i}+L_{u}\right)=w_{a}\left(L-L_{a}\right) .
$$


Figure 1. Labor Allocation Mechanism.

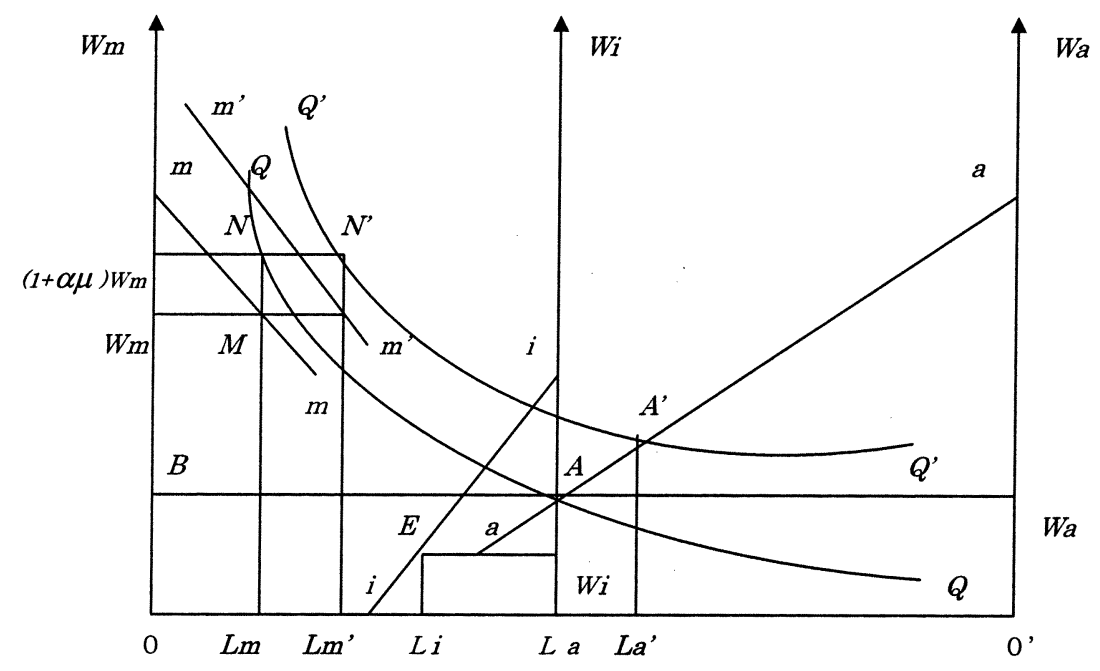

Thus, the labor allocation between urban and rural areas is given at the intersection of $a a$ and the rectangular hyperbola $Q Q$ through point $N$. This is because the nature of the rectangular hyperbola ensures that the area $0(1+\alpha \mu) w_{m}$ $N L_{m}$ is equal to the area $0 B A L_{a}$. Therefore, it can be seen that $0^{\prime} L_{a}$ is employed in the agricultural sector and $0 L_{a}$ stays in the urban area.

Now let us focus our attention to the labor allocation within the urban area. From (4) and (7), the employment in the informal sector is determined at point $E$, that is, the intersection of the marginal value product of the informal sector $i i$ and the given $w_{i}\left(=\alpha w_{m}\right)$. Thus, the figure shows that $L_{a} L_{i}$ is employed in the informal sector and $L_{i} L_{m}$ remains unemployed.

It is assumed that capital is sector specific in the rural and informal sector so that $K_{a}=\bar{K}_{a}$ and $K_{i}=\bar{K}_{i}$, whereas the total employment of capital in the manufacturing sector $\left(K_{m}\right)$ is given by

$$
K_{m}=\bar{K}_{m}+K_{m}^{*},
$$

where $\bar{K}_{j}$ is the fixed endowment of domestic capital in the $j$ th sector $(j=a, i, m)$ and $K_{m}^{*}$ is the inflow of foreign capital.

We assume that the informal good is a pure intermediate good and the output of the sector is used up in the urban manufacturing sector. Thus, we have 


$$
R=X_{i}
$$

It may be more realistic to consider consumption goods and/or services as informal products in developing countries. Here, however, we focus our attention to another aspect of informal sectors. We suppose relatively industrialized developing economies that have still dual structure, such as Asian NIEs and India. In these economies, the informal sector consists of many subcontract firms. They produce various parts and semi-processed components for the parent firms. Such subcontract firms are observed around machine and automobile makers in various countries. These activities also have typical characteristic features of informal sectors, such as small scale, easy entry and among others a low-wage rate suppressed by the parent firms as pointed out by Beladi and Yabuuchi (2001).

Since the informal good is non-traded in the present setup, the price $(q)$ is determined through the equilibrium condition for the informal good market. This completes the specification of our model. We have fourteen unknown variables, $w_{i}, w_{a}, r_{m}, r_{i}, r_{a}, L_{a}, L_{m}, L_{i}, \mu, L_{u}, \lambda, q, R$ and $K_{m}$, which are solved by twelve equations (4) - (15) and the definitions of $\mu$ and $\lambda$ for given parameters, $w_{m}, p, \bar{K}_{a}, \bar{K}_{i}, L, \alpha$ and $K_{m}^{*}$.

Finally, we suppose that $F_{R L}^{m}=F_{R K}^{m}=0$, that is, the intermediate input is technically independent of either labor or capital in the manufacturing production. This is partly justified by the fact that four tires are used to produce a car and one Brown tube is used for a TV set.

\section{Foreign Investment and Unemployment}

Differentiating (4) - (15) and the definitions of $\mu$ and $\lambda$, and arranging terms with respect to the important variables, we obtain

$$
\left[\begin{array}{ccccc}
0 & p F_{L L}^{m} & 0 & 0 & 0 \\
-1 & p F_{K L}^{m} & 0 & 0 & 0 \\
0 & \mu q F_{L L}^{i} / F_{L}^{i} & 0 & q F_{L L}^{i} L_{m} / F_{L}^{i} & 0 \\
0 & 1+\mu+\lambda & 1 & L_{m} & L_{m} \\
0 & 0 & -(1+\mu+\lambda) F_{L L}^{a} & \left(w_{i}-w_{a}\right) & -w_{a}
\end{array}\right]\left[\begin{array}{c}
d r_{m} \\
d L_{m} \\
d L_{a} \\
d \mu \\
d \lambda
\end{array}\right]=\left[\begin{array}{c}
-p F_{L K}^{m} \\
-p F_{K K}^{m} \\
0 \\
0 \\
0
\end{array}\right] d K_{m}^{*}
$$


Solving this for $d \lambda$ with respect to $d K_{m}^{*}$, we have

$$
d \lambda / d K_{M}^{*}=\left\{\mu\left(w_{i}-\Omega\right)-(1+\mu+\lambda)^{2} F_{L L}^{a} L_{m}\right\} p F_{L K}^{m} q F_{L L}^{i} / F_{L}^{i} \Delta,
$$

where $\Delta$ is the value of the determinant of the coefficient matrix (16),

$$
\Delta=\Omega p F_{L L}^{m} q F_{L L}^{i} L_{m} / F_{L}^{i}>0 \text {, and } \Omega=w_{a}-(1+\mu+\lambda) F_{L L}^{a} L_{m} .
$$

Similarly, we have the effects of foreign investment on employment as follows.

$$
\begin{gathered}
d L_{m} / d K_{m}^{*}=-F_{L K}^{m} / F_{L L}^{m}>0, \\
d L_{a} / d K_{m}^{*}=p F_{L K}^{m} L_{m} w_{m} q F_{L L}^{i} / F_{L}^{i} \Delta<0, \\
d L_{i} / d K_{m}^{*}=L_{m} d \mu / d K_{m}^{*}+\mu d L_{m} / d K_{m}^{*}=0 .
\end{gathered}
$$

Thus, the following proposition is immediate.

Proposition 1. Foreign investment into the urban formal sector increases the employment of the sector and decreases that of the rural agricultural sector, while it leaves the employment of the informal sector constant.

Since the informal wage rate is fixed owing to some institutional reason stated above, the employment in the sector is constant. This implies that the output is also constant. The capital inflow raises the marginal value product of labor in the manufacturing sector. This is shown as the shift of the curve from $m m$ to $m$ ' $m$ ' in Figure 1. This increases the manufacturing employment to $L_{m}^{\prime}$. On the other hand, the agricultural employment decreases to $L_{a}^{\prime}$ according to the labor allocation mechanism.

Now we examine the effect of the investment on unemployment. By definition, we have

$$
d L_{u} / d K_{m}^{*}=\lambda d L_{m} / d K_{m}^{*}+L_{m} d \lambda / d K_{m}^{*} .
$$

Substituting (17) and (18) into (21), we obtain

$$
d L_{u} / d K_{m}^{*}=\left(\Omega-w_{m}\right) p F_{L K}^{m} q F_{L L}^{i} L_{m} / F_{L}^{i} \Delta
$$

This leads to the following proposition. 
Proposition 2. Foreign investment into the urban formal sector reduces urban unemployment if and only if $w_{m}<\Omega$.

The capital inflow increases employment of the urban formal sector owing to the increase in the marginal product of labor in the sector. This increase in urban employment increases the expected urban wage rate. Thus, some of the rural workers go to the city, and then this reduces rural employment. We have shown that the employment of the urban informal sector is unchanged due to the capital inflow. If the increase in employment in the formal sector is larger than the migrants from the rural area, therefore, some of the migrants will be absorbed in the unemployment pool. Proposition 3 provides the precise condition for the result. The condition can be written as

$$
w_{m}<w_{a}-(1+\mu+\lambda) F_{L L}^{a} L_{m}
$$

Thus, it implies that (1) if the rural wage rate is relatively large with respective to the manufacturing wage rate, and (2) if the rural employment is sensitive to the change in the rural wage rate (i.e., $F_{L L}^{a}$ is large), the decrease in the rural employment becomes small with respect to a given increase in the manufacturing employment. Therefore, the necessary workers in agriculture must be supplied from the unemployment pool. This leads to a decrease in urban unemployment.

\section{Foreign Investment and Welfare}

Now we investigate the implications of capital inflow for output and welfare. The demand side of the model is represented by a quasi-concave social utility function. Let $U$ denote the social utility that depends on the consumption demand for agricultural and manufacturing goods denoted by, $D_{a}$ and $D_{m}$, respectively. Thus,

$$
U=U\left(D_{a}, D_{m}\right)
$$

The balance of trade equilibrium requires that

$$
D_{a}+p^{*} D_{m}=X_{a}+p^{*} X_{m}-r_{m} K_{m}^{*} .
$$


Differentiating (23) and (24) yields (see the Appendix)

$$
\begin{aligned}
\left(R / U_{a}\right)\left(d U / d K_{m}^{*}\right) & =-t p^{*}\left(d X_{m} / d K_{m}^{*}\right)+\left[L _ { m } \left\{\left(w_{i}-w_{a}\right)\left(d \mu / d K_{m}^{*}\right)\right.\right. \\
& \left.\left.-w_{a}\left(d \lambda / d K_{m}^{*}\right)\right\}-K_{m}^{*}\left(d r_{m} / d K_{m}^{*}\right)\right]
\end{aligned}
$$

where $R=\{1+(1-m) t\} /(1+t), m$ is the marginal propensity to consume the manufacturing good, and $U_{a}=\partial U / \partial D_{a}$.

Comparative statics shows that

$$
\begin{gathered}
d \mu / d K_{m}^{*}=\mu F_{L K}^{m} / L_{m} F_{L L}^{m}<0, \\
d r_{m} / d K_{m}^{*}=p\left\{F_{L L}^{m} F_{K K}^{m}-\left(F_{L K}^{m}\right)^{2}\right\} / F_{L L}^{m}=0,
\end{gathered}
$$

since $\left\{F_{L L}^{m} F_{K K}^{m}-\left(F_{L K}^{m}\right)^{2}\right\}=0$ under the assumptions that $F_{R L}^{m}=F_{R K}^{m}=0$ and the production function is homogeneous to degree one.

First, we examine the effect of foreign investment on the output of the manufacturing sector. Differentiating the production function, we have

$$
p\left(d X_{m} / d K_{m}^{*}\right)=\left(w_{m}+\mu w_{i}\right)\left(d L_{m} / d K_{m}^{*}\right)+w_{i} L_{m}\left(d \mu / d K_{m}^{*}\right)+r_{m}
$$

Substituting (18) and (26) into (28) yields

$$
\left(d X_{m} / d K_{m}^{*}\right)=-F_{L K}^{m}\left(w_{m} L_{m}+r_{m} K_{m}\right) / p F_{L L}^{m} L_{m}>0 .
$$

Thus, we have the following proposition.

Proposition 3. Foreign investment into the urban formal sector increases the output of the sector.

Now we are ready to see the implication of foreign investment for welfare. Substituting (17), (26) and (27) into (25), we obtain

$$
\begin{gathered}
\left(R / U_{a}\right)\left(d U / d K_{m}^{*}\right)=t p^{*} F_{L K}^{m}\left(w_{m} L_{m}+r_{m} K_{m}\right) / p F_{L L}^{m} L_{m} \\
+w_{m}\left(L_{m}\right)^{2}(1+\mu+\lambda) F_{L L}^{a} p F_{L K}^{m} q F_{L L}^{i} / F_{L}^{i} \Delta .
\end{gathered}
$$


This leads to the following proposition.

Proposition 4. Foreign investment into the urban formal sector is immiserizing if and only if

$$
t>-L_{m}(1+\mu+\lambda) F_{L L}^{a} \theta_{L}^{m} / p^{*} \Omega,
$$

where $\theta_{L}^{m}=w_{m} L_{m}\left(w_{m} L_{m}+r_{m} K_{m}\right)$.

Foreign investment increases the output of the manufacturing sector that is distorted by the tariff. This effect is captured by the first term of the RHS of (30), and it is harmful to the welfare. On the other hand, the investment has positive income effect since it increases the employment of the high wage-manufacturing sector and decreases that of the low wage agricultural sector. Proposition 4 provides the precise condition for the immiserization. The higher the tariff (i.e., the larger the distortion), and the more sensitive the rural employment with respect to the change in the rural wage rate (i.e., the smaller $\left(-F_{L L}^{a}\right)$ ), the larger is the likelihood of immiserization. If the tariff rate is high, the negative distortion cost may dominate the positive income effect. If the sensitivity of the rural employment is high, the decrease in the rural employment is large. Thus, the positive income effect becomes small. Conversely, if the tariff rate is smaller than the critical value, foreign investment improves welfare even under the situation supposed by Uzawa (1969), Hamada (1973), and Brecher and Alejandro (1977)

Grinols (1991) showed the possibility of welfare improvement due to the economic contribution by workers employed in the informal sector whose opportunity costs are considerably low. We have shown that there is another possibility of welfare improvement owing to labor allocation in the model with both an informal sector and unemployment.

\section{Income Distribution}

In this section, we investigate the implication of foreign investment for income distribution. Wage income is expressed as $w_{a} L_{a}+w_{m} L_{m}+w_{i} L_{i}=w_{a} L$ since $\left(w_{m}\right.$ $\left.L_{m}+w_{i} L_{i}\right)=w_{a}\left(L_{m}+L_{i}+L_{u}\right)$. Thus, the change in wage income depends solely on the change in the rural wage rate since the endowment of labor $(L)$ is constant. From (17), we have 


$$
d w_{a} / d K_{m}^{*}=F_{L L}^{a}\left(d L_{a} / d K_{m}^{*}\right)>0 .
$$

On the other hand, the change in capital income $\left(r_{m} \bar{K}_{m}+r_{i} \bar{K}_{i}+r_{a} \bar{K}_{a}\right)$ depends solely on the change in the rental of rural capital since each sector-specific capital is constant and $d r_{m} / d K_{m}^{*}=F_{K L}^{a}\left(d L_{a} / d K_{m}^{*}\right)<0$. Furthermore, from (11) and (19), we obtain

$$
d r_{a} / d K_{m}^{*}=F_{K L}^{a}\left(d L_{a} / d K_{m}^{*}\right)<0 .
$$

The following proposition summarizes the results.

Proposition 5. Foreign investment into the urban formal sector redistributes income from capital to labor.

Wage income of urban formal sector increases owing to the increase in the employment, while that of urban informal sector is unchanged. The change in wage income of the rural sector depends on the elasticity of labor demand in the sector with respect to the rural wage rate. Wage income of the rural sector increases if and only if the elasticity of labor demand is less than one since

$$
d\left(w_{a} L_{a}\right) / d K_{m}^{*}=L_{a}\left(1-\xi_{L}^{a}\right)\left(d w_{a} / d K_{m}^{*}\right)
$$

where $\xi_{L}^{a}=-w_{a} / L_{a} F_{L L}^{a}$. Anyway, the result shows that the total wage income increases definitely owing to the increase in the employment in the high wagemanufacturing sector. On the other hand, the total capital income decreases through the decrease in the rental of rural capital.

\section{Concluding Remarks}

We have reexamined the effects of foreign investment in the model with an informal sector and unemployment. We have paid particular attention to the possibility of immiserizing growth under some distorted condition.

It has been shown that the investment increases the output of the invested sector, it may decrease unemployment, and it redistributes national income from capital to labor. In addition, we have shown that there is a possibility of welfare improvement contrary to the conventional wisdom. Thus, our result is more favorable than 
the traditional one for developing countries. In this sense, our analysis is consistent with much empirical evidence that emerging economies intend to industrialize introducing foreign capital intensively.

However, our results depend on several assumptions that capital is specific to the respective sector, the informal wage rate is constant $\left(w_{i}=\alpha w_{m} ; 0<\alpha<1\right)$, and the intermediate input is technically independent of either labor or capital in the manufacturing production $\left(F_{R L}^{m}=F_{R K}^{m}=0\right)$. Therefore, some qualification must be needed to evaluate and apply the results obtained in this paper. At the same time, it would constitute an important agenda for the further research in this area to relax these assumptions.

\section{Appendix}

Here we derive the equation (25) in the text. Differentiating (23) and (24), we have

$$
\begin{aligned}
d U / U_{a} & =d D_{a}+p d D_{m} \\
& =\left(d X_{a}+p d X_{m}-r_{m} d K_{m}^{*}-K_{m}^{*} d r_{m}\right)+t p^{*} d M,
\end{aligned}
$$

where $M\left(=D_{m}-X_{m}\right)$ is the import demand for the manufacturing good. Differentiating the import demand function $M$, and considering the manufacturing price $(p)$ is constant, we obtain

$$
d M=\left\{(m / p)\left(d X_{a}+p d X_{m}-r_{m} d K_{m}^{*}-K_{m}^{*} d r_{m}\right)-d X_{m}\right\} / R,
$$

where $m$ is the marginal propensity to consume the manufacturing good, and $R=\{1+(1-m) t\} /(1+t)$.

Substituting (A2) into (A1), we have

$$
R d U / U_{a}=\left(d X_{a}+p d X_{m}-r_{m} d K_{m}^{*}-K_{m}^{*} d r_{m}\right)-t p^{*} d X_{m}
$$

Differentiating (1) - (3), and considering (6) - (8), we have

$$
\begin{aligned}
& d X_{a}+p d X_{m}-r_{m} d K_{m}^{*}-K_{m}^{*} d r_{m} \\
& =w_{a} d L_{a}+w_{m} d L_{m}+w_{i} d L_{i}-K_{m}^{*} d r_{m} .
\end{aligned}
$$

Considering (5), we can show 


$$
w_{m} d L_{m}+w_{i} d L_{i}=L_{m}\left(w_{i}-w_{a}\right) d \mu-L_{m} w_{a} d \lambda-w_{a} d L_{a} .
$$

Thus, from (A3), (A4) and (A5), we have

$$
R d U / U_{a}=-t p^{*} d X_{m}+\left[L_{m}\left\{\left(w_{i}-w_{a}\right) d \mu-w_{a} d \lambda\right\}-K_{m}^{*} d r_{m}\right]
$$

This leads to the equation (25) in the main text.

\section{Acknowledgement}

The authors would like to express their appreciation to an anonymous referee for many helpful comments and suggestions.

Received 16 December 2002, Accepted 25 September 2003

\section{References}

Beladi, H. and S. Marjit (1992), "Foreign capital and protectionism", Canadian Journal of Economics 25, 233-238.

Beladi, H. and S. Marjit (2000), "A general equilibrium analysis of foreign investment and intersectoral linkage", Journal of International Trade and Economic Development 9, 213-218.

Beladi, H. and S. Yabuuchi (2001), "Tariff-induced capital inflow and welfare in the presence of unemployment and informal sector", Japan and the World Economy 13, 51-60.

Bhagwati, J. N. (1958), "Immiserizing growth: A geometric note", Review of Economic Studies 25, 201-205.

Bhagwati, J. N. (1968), "Distortions and immiserizing growth: A generalization", Review of Economic Studies 35, 481-485.

Bhagwati, J. N. (1973), "The theory of immiserizing growth: Further application", in M. B.Connolly and A. K. Swoboda eds., International Trade and Money (University of Toronto Press) 45-54.

Brecher, R.A. and C.F. Diaz Alejandro (1977), "Tariffs, foreign capital and immiserizing growth", Journal of International Economics 7, 317-322.

Brecher, R.A. and R. Findlay (1983), "Tariffs, foreign capital and immiserizing growth", Journal of International Economics 7, 317-322.

Casas, F. R. (1985), "Tariff protection and taxation of foreign capital: the welfare implications for a small country", Journal of International Economics 19, 181-188.

Chandra, V. and M. A. Khan (1993), "Foreign investment in the presence of an informal sector", Economica 60, 79-103. 
Chao, C. C. and E. S. H. Yu (1991), "Immiserizing growth for a quota-distorted small economy under variable returns to scale", Canadian Journal of Economics 24, 686692.

Chao, C. C. and E. S. H. Yu (1994), "Foreign capital inflows and welfare in an economy with imperfect competition", Journal of Development Economics 45, 141-154.

Chao, C. C. and E. S. H. Yu (1996), "International capital mobility, urban unemployment and welfare", Southern Economic Journal 62, 486-492.

Dei, F. (1985), "Welfare gains from capital inflows under import quotas", Economics Letters 18, 237-240.

Din, Musleh (1996), "International capital mobility and development policy in a dual economy", Review of International Economics 4, 185-201.

Grinols E. L. (1991), "Unemployment and foreign capital: the relative opportunity costs of domestic labor and welfare", Economica 58, 107-121.

Gupta, M. R. (1994), "Foreign capital, income inequality and welfare in a Harris-Todaro model", Journal of Development Economics 45, 407-414.

Gupta, M. R. (1995), "Tax on foreign capital income and wage subsidy to the urban sector in the Harris-Todaro model", Journal of Development Economics 47, 469-479.

Hamada, K. (1973), "An economic analysis of the duty free zone", Journal of International Economics 4, 225-241.

Hamilton, C. and L. O. Svensson (1982), "On the welfare effects of a duty free zone", Journal of International Economics 13, 45-64.

Harris, J. R. and M. Todaro (1970), "Migration, unemployment and development: A twosector analysis", American Economic Review 60, 126-142.

Johnson, H. G. (1967), "The possibility of income losses from increased efficiency or factor accumulation in the presence of tariffs", Economic Journal 77, 151-154.

Khan, M. A. (1982), "Tariffs, foreign capital and immiserizing growth with urban unemployment and specific factors of production", Journal of Development Economics 10, 245-256.

Miyagiwa, K. (1986), "A reconsideration of the welfare economics of a free-trade zone", Journal of International Economics 21, 337-350.

Miyagiwa, K. (1993), "The locational choice for free-trade zones", Journal of Development Economics 40, 187-203.

Rodriguez, C. A. (1976), "A note on the economics of the duty free zones," Journal of International Economics 6, 385-388.

Uzawa, H. (1969), "Liberalization of foreign investments and the national economy", Ekonomisuto 23, 106-122 (in Japanese).

Yabuuchi, S. (1982), "A note on tariff-induced capital inflow and immiserization in the presence of foreign profits", Journal of International Economics 12, 183-189.

Yabuuchi, S. (1993), "Urban unemployment, international capital mobility and development policy", Journal of Development Economics 41, 399-403.

Yabuuchi, S. (1997), "Direct investment, monopoly and welfare", Pacific Economic Review 2, 135-141. 
Young, L. (1987), "Intermediate goods and the formation of duty-free zones", Journal of Development Economics 25, 369-384.

Young, L. (1992), "Unemployment and the optimal export-processing zone", Journal of Development Economics 37, 369-385.

Young, L. and K. Miyagiwa (1987), "Unemployment and the formation of the duty-free zones", Journal of Development Economics 26, 397-405. 